\title{
MATHEMATICAL MODELING OF UNSATURATED ISOPHTHALIC RESIN'S CURING CYCLE
}

\section{RAVI KUMAR. V \& PRAKASH. K. R}

${ }^{I}$ Department of Mechanical Engineering, Amrita School of Engineering, Bengaluru, Amrita Vishwa Vidyapeetham, India

${ }^{2}$ Department of Mechanical Engineering, National Institute of Engineering, Mysore, India

ABSTRACT
Fiber reinforced plastics (FRP) products are light weighing and strong. These materials find extensive
applications in various engineering fields and also as sensor metarial. Curing of this resin is a key to obtain FRP
Products. Various factors including Gel time $\left(T_{\text {gel }}\right)$ and peak exothermic temperature $\left(T_{\text {peak }}\right.$ ) are the critical factors that
directly affect the curing process. $T_{\text {gel }}$ is the indicator for the commencement of setting (polymer cross-linking) while $T_{\text {peak }}$
talks about the shrinkage and cracking of the polymer. This research work finds the $T_{\text {gel }}$ and $T_{\text {peak }}$ for the curing of UP
resin based isophthalic acid. The Catalyst MEKP (methyl ethyl ketone peroxide). The accelerator cobalt octoate (Cost)
were used for the curing process. Results showed strong interactions between the process variables mentioned above. The
process was anoptimization to achieve a combination of $T_{\text {gel }}$ and $T_{\text {peak } \text { within the regime of experimentation. }}$
Mathematical models were developed using regression for both peak temperature and gel time. Confirmatory experiments
were performed to validate the predicted results.
KEYWORDS: Curing, Gel time, Peak exothermic temperature, ISO Resin, FRP, Process Optimization

Received: Feb 01, 2018; Accepted: Feb 22, 2018; Published: Mar 14, 2018; Paper Id.: IJMPERDAPR201891

\section{INTRODUCTION}

One of the important thermoset resin is the unsaturated polyester resins which are basically macromolecules [1] with a polyester. The resin has medium viscosity. In specific the iso phthalic acid based resin shows excellent mechanical properties along with good chemical resistance. As any polyester resin, iso resin also has styrenes ( $45 \%$ to $48 \%$ by volume ) as the monomer. In which the polyester molecule are dissolved. A peroxide compound, usually methyl ethyl ketone peroxide (MEKP) is used to catalyze the resin [2], which cross-links with some of the styrenes, but not all of it.

The UP resins shall be easily processed in filament winding hand layup process, resin transfer molding [3]. They can also widely used as a molding compound. Hence, these UP resins are used in a different fields like insulation coatings [4], widely used in making fiber reinforced plastics (FRP) products, plastic sandwich panels, pultrusion components $[5,17]$ etc.

The curing process of UP resin happens due to chemical kinetics [6] and the same will be controlled by diffusion. The curing between styrene monomer and UP mainly occurs because of free radical chain -growth [7]. During this process at room temperature, the organic peroxides (like methyl ethyl ketone peroxide (MEKP)) are abundantly used as catalysts[8] Meanwhile cobalt salt is mostly used as an accelerator [8]. The inhibitors of 
quinones and phenol [9] are mixed to react with the most of or propagating radicals [10] to reduce the effect of reactivity. This gives storage life [11]. The achievement of preparing an FRP product by a hand lay -up the process [12] are mainly depends on the curing kinetics [14] and also the gel time. The complete interaction of chemical kinetics and physical phenomena like gelling process makes this curing process [15] highly complex[16].

\section{MATERIALS AND EXPERIMENTAL SETUP}

The resin used for the proposed work is a commercially available general purpose Unsaturated Polyester (UP) resin based on isophthalic acid formulated by Naptha Resins and Chemicals (P) Limited, India under the trade name 'Polyflex Gr 200-220'. The resin was found to have the properties as shown in table 1 below. The curing process consists of MEKP. This curing process was carried out at room temperature $\left(26 \pm 2^{\circ} \mathrm{C}\right)$ with a precalculated quantity of MEKP and Cost,. A cylindrical mold of diameter $67 \mathrm{~mm}$ and height $36 \mathrm{~mm}$ made up of Stainless steel was used to complete the curing process. This device consists of a steel plunger oscillator which slides over the vertical column of the fixture which has the tapered end. In other hands the other end of the column is rested against a dial gauge to record the displacement of the plunger (depth of penetration). At this time, the reaction was started to turning to be stable condition. Figure 1, clearly shows the gel time indicator. We can also observe rise the temperature during curing process because of the exothermic reactions. This rise in temperature caused by this process successfully was monitored by using a thermocouple and the same was noted during this process. Figure2 shows a clear time-temperature graphs for the process.

Table 1: Properties of the Resin

\begin{tabular}{|l|l|}
\hline \multicolumn{1}{|c|}{ Property } & \multicolumn{1}{c|}{ Value } \\
\hline Colour & Clear Liquid \\
\hline Viscosity @ $25^{\circ} \mathrm{C}$ & $540 \mathrm{cps}$ \\
\hline Acid value & $10.46 \mathrm{mg} \mathrm{KOH} / \mathrm{g}$ \\
\hline Volatile Content $\left(2 \mathrm{~g} / 150^{\circ} \mathrm{C} / \mathrm{hr}\right)$ & $39.36 \%$ \\
\hline $\begin{array}{l}\text { Gel Time @ } 25^{\circ} \mathrm{C} \\
\text { Resin quantity } 100 \text { gms with 3\% } \\
\text { accelerator and 3\% catalyst }\end{array}$ & $12{ }^{\prime} 35^{\prime}$, \\
\hline
\end{tabular}

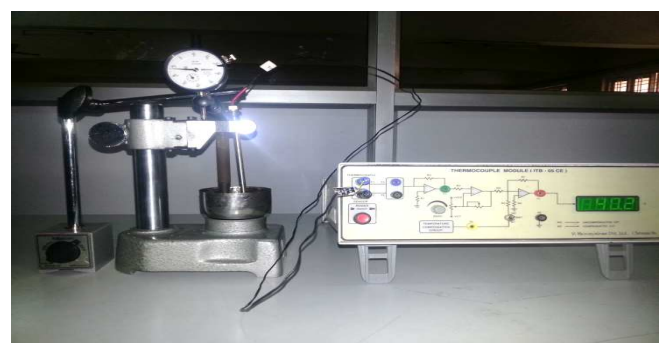

Figure 1: The Softness Indicator Setup

\section{RESULTS AND DISCUSSIONS}

Polymerization mechanism of UP resin with styrene as a cross -linking monomer is well known, which cleared that the UP resin is reacted with carbon-carbon covalent bonds, the same can be successfully cross-linked to form a sound thermosetting material. It is successfully achieved with the help of vinyl group molecules, namely styrenes in the good presence of MEKP catalyst and Cost accelerator. This process results in achieving a cross -link between the polymer chains and which results in the formation of a 3D, strong and sound polymer. The graphs below shows the variation of the temperature and penetration depth as a function of time for a few samples tested. Cross-linking mechanisms of polymer 
chains were observed and recorded successfully which is shown in Table 2.

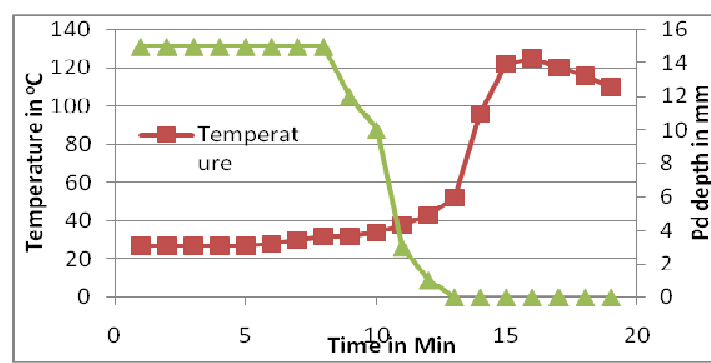

Figure 2(a): 4\% cobalt and 5\% MEKP

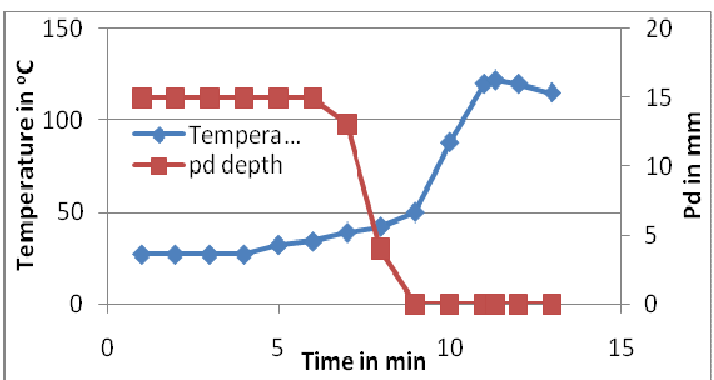

Figure 2(c): 5\% Cobalt and 5\% MEKP

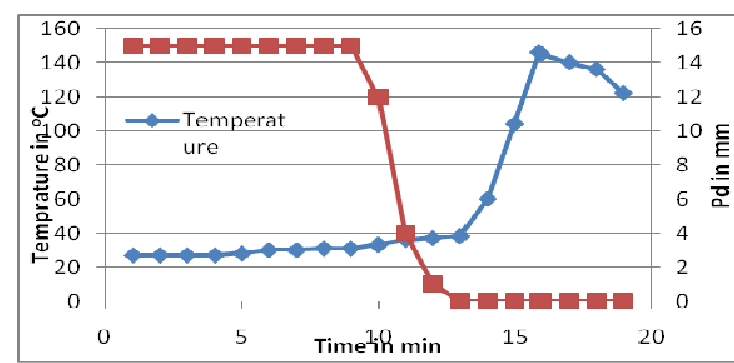

Figure2 (b): 5\% Cobalt and 4\% MEKP

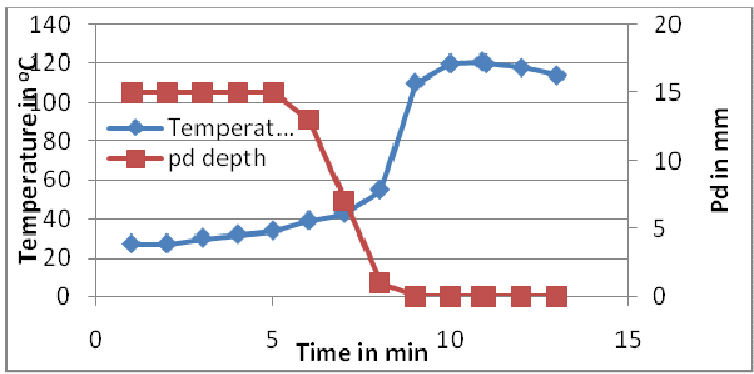

Figure (2d) 5\% Cobalt and 6\% MEKP

Figure $2 \mathrm{a}, \mathrm{b}, \mathrm{c} \& \mathrm{~d}$. Time - Temperature and penetration depth curves for different $\%$ of accelerator and catalyst.

Table 2: Peak Temp \& Gel Time for Various Combination of Accelerator and Catalyst

\begin{tabular}{|c|c|c|c|c|}
\hline Sl. No. & $\begin{array}{c}\text { Accelerator } \\
\text { as \% wt }\end{array}$ & $\begin{array}{c}\text { Hardener } \\
\text { as \% wt }\end{array}$ & $\begin{array}{c}\text { Peak temp } \\
\left({ }^{\mathbf{0}} \mathbf{C}\right)\end{array}$ & $\begin{array}{c}\text { Gel Time } \\
(\mathbf{S e c})\end{array}$ \\
\hline 1 & 3 & 3 & 132 & 980 \\
\hline 2 & 4 & 3 & 128 & 910 \\
\hline 3 & 3 & 4 & 127 & 664 \\
\hline 4 & 4 & 4 & 133 & 647 \\
\hline 5 & 5 & 4 & 146 & 595 \\
\hline 6 & 4 & 5 & 125 & 546 \\
\hline 7 & 5 & 5 & 122 & 375 \\
\hline 8 & 6 & 5 & 130 & 369 \\
\hline 9 & 5 & 6 & 121 & 325 \\
\hline 10 & 6 & 6 & 100 & 310 \\
\hline 11 & 5 & 3 & 135 & 493 \\
\hline 12 & 6 & 3 & 131 & 465 \\
\hline 13 & 6 & 4 & 131 & 335 \\
\hline 14 & 3 & 5 & 126 & 420 \\
\hline 15 & 3 & 6 & 133 & 332 \\
\hline 16 & 4 & 6 & 128 & 350 \\
\hline
\end{tabular}

Figure 3. Is a surface graph representing an interaction between catalyst and accelerator with a decreasing trend in $T_{\text {gel }} \mathrm{T}_{\text {gel }}$ is approximately $980 \mathrm{sec}$ at the lowest levels $(3 \%, 3 \%)$ of catalyst and accelerator, which reduced to $310 \mathrm{sec}$ at their highest levels $(6 \%, 6 \%)$. It can be clearly observed that for a taken level of accelerator concentration; the used catalyst results in a noticeable reduction in the $T_{\text {gel }}$. This is clearly because of increase in free radicals formed due to the decomposition of the catalyst with the help of accelerator. These free radicals formed during this process also the reason behind exothermic copolymerization reaction. During this process, the temperature rises. Also in other hands the 
accumulation of heat energy results in increasing the rate of this reaction and rise in polymer molecular weight steadily.

From the bellow plots, we can clearly predict that for a taken level of catalyst, $T_{\text {gel }}$ is very highly sensitive to use of low percentage of the accelerator and also confirms the sensitivity decreases to good extent and later it becomes almost constant for next percentage of an accelerator. This is claimed to be normal for a fixed level of catalyst controls the formation of free radicals that are the reason why we see an increasing trend at low percentages of an accelerator, as the catalyst is sufficient enough to produce free radicals by decomposition. The $T_{\text {gel }}$ is less sensitive towards the increased percentage of accelerator this is due to the fact that the excess of accelerator present has already decomposed the catalyst available and hence decomposition has substantially completed, which intern means reduced levels of free radicals.

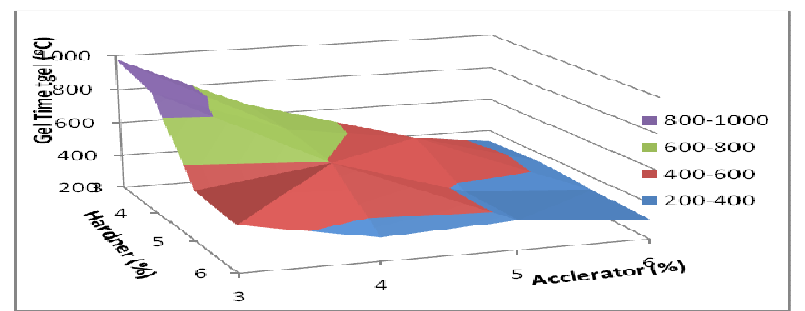

Figure 3: Surface Plot Showing Variatation of grl Time as a Function of Accelerator and Catalyst(Hardner)

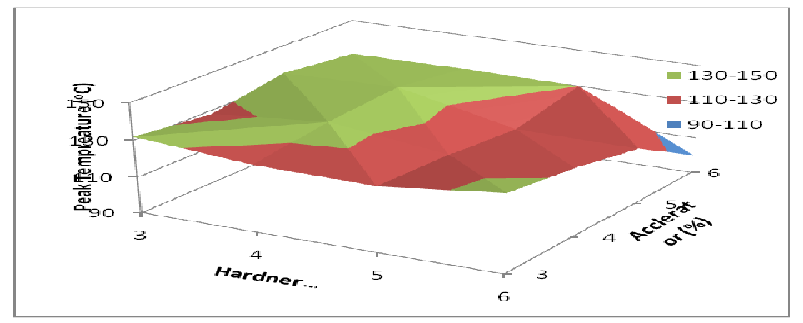

Figure 4: Surface Plot Showing Variatation of Peak Temperature as a Function of Accelerator and Catalyst(Hardner)

Figure 4 above indicates the variation of the peak temperature with respect to the various combination of the accelerator and the catalyst. It can be noted that the increase in the accelerator levels does not contribute significantly towards the peak temperature at various levels of the catalyst. The higher the percentage of the catalyst the lesser is the peak temperature, i.e., the temperature reduces to $100^{\circ} \mathrm{C}$ at the highest levels of the catalyst.

\section{Mathematical Model}

A Mathematical model was developed to predict the Gel time for a different combination of Accelerator and Hardener. The summary output of the regression analysis is given below. The significance $\mathrm{F}$ is well below 0.05 which indicates that the considered parameters affect our measured output considerably and the $\mathrm{P}$ values for the different factors and their combination is less than 0.05 which means they are significant. The R square and Adjusted R square value is $90 \%$ which indicates that the mathematical model is close to the actual model and it can be further used to predict the Gel time for the different combination of Accelerator and Hardener. The mathematical model for Gel time is given below.

$\mathrm{T}_{\text {gel }}=2749.42-370 \mathrm{~A}-412 \mathrm{H}+63.28 \mathrm{AH}$

Where $\mathrm{A}$ - Accelerator and $\mathrm{H}$ - Hardener 
It was also observed that the predicted values are having less than $5 \%$ error.

\begin{tabular}{|l|c|}
\hline \multicolumn{2}{|c|}{ SUMMARY } \\
\hline Regression Statistics & 0.945370763 \\
\hline Multiple R & 0.893725879 \\
\hline R Square & 0.867157349 \\
\hline Adjusted R Square & 75.42912788 \\
\hline Standard Error & 16 \\
\hline Observations & \\
\hline
\end{tabular}

\begin{tabular}{|c|c|c|c|c|c|}
\hline ANOVA & df & SS & MS & F & Significance F \\
\hline Regression & 3 & 574164.36 & 191388.1 & 33.6385141 & $4.02781 \mathrm{E}-06$ \\
\hline Residual & 12 & 68274.64 & 5689.553 & & \\
\hline Total & $\mathbf{1 5}$ & $\mathbf{6 4 2 4 3 9}$ & & & \\
\hline
\end{tabular}

\begin{tabular}{|l|c|c|c|c|c|}
\hline & Coefficients & Standard Error & t Stat & P-value & Lower 95\% \\
\hline Intercept & 2749.42 & 324.3452499 & 8.476831 & $2.0685 \mathrm{E}-06$ & 2042.732408 \\
\hline Accelerator as \% wt & -370.16 & 69.95009554 & -5.29177 & 0.00019089 & -522.5681656 \\
\hline Hardener as \% wt & -412.86 & 69.95009554 & -5.90221 & $7.228 \mathrm{E}-05$ & -565.2681656 \\
\hline Acc*Hard & 63.28 & 15.08582558 & 4.194666 & 0.00124364 & 30.41080969 \\
\hline
\end{tabular}

In a similar manner, regression analysis was done for peak temperature. The following is the summary of the regression analysis done for peak temperature.

\begin{tabular}{|l|c|}
\hline \multicolumn{2}{|c|}{ SUMMARY } \\
\hline \multicolumn{2}{|c|}{ Regression Statistics } \\
\hline Multiple R & 0.722481257 \\
\hline R Square & 0.521979167 \\
\hline Adjusted R Square & 0.402473958 \\
\hline Standard Error & 7.316989363 \\
\hline Observations & 16 \\
\hline
\end{tabular}

\begin{tabular}{|c|c|c|c|c|c|}
\hline ANOVA & df & SS & MS & F & Significance F \\
\hline Regression & 3 & 701.54 & 233.8467 & 4.367836 & 0.026849984 \\
\hline Residual & 12 & 642.46 & 53.53833 & & \\
\hline Total & $\mathbf{1 5}$ & $\mathbf{1 3 4 4}$ & & & \\
\hline
\end{tabular}

\begin{tabular}{|l|c|c|c|c|c|}
\hline & Coefficients & Standard Error & t Stat & P-value & Lower 95\% \\
\hline Intercept & 84.26 & 31.46305 & 2.678062 & 0.020109 & 15.70789372 \\
\hline Accelerator as \% wt & 13.87 & 6.785497 & 2.044066 & 0.063534 & -0.914327458 \\
\hline Hardener as \% wt & 11.42 & 6.785497 & 1.683001 & 0.118189 & -3.364327458 \\
\hline Acc*Hard & -3.46 & 1.463398 & -2.36436 & 0.035767 & -6.64847006 \\
\hline
\end{tabular}

The mathematical model for peak temperature is given below.

$\mathrm{T}_{\text {peak }}=84.26+13.87 \mathrm{~A}+11.42 \mathrm{H}-3.46 \mathrm{AH}$.

\section{CONCLUSIONS}

The lower $\mathrm{T}_{\text {gel }}$ Value will result in defects like incomplete mold filling as at $\mathrm{T}_{\text {gel }}$ mobility is arrested in the polymer, while a higher value will increase the cycle time and reduce the productivity. Similarly, lower $\mathrm{T}_{\text {peak }}$ can slow down the reaction rate and hence have longer curing times, while the higher values may result in distortion of the part due to shrinkage and cracking. Thus the values of $\mathrm{T}_{\text {gel }}$ and $\mathrm{T}_{\text {peak }}$, should be neither too less nor too high. This will ensure proper 
curing cycles. Hence the values of both $\mathrm{T}_{\text {gel }}$ and $\mathrm{T}_{\text {peak }}$ play an important role in the curing process of a polymer composite. The preferred levels of this are around $600 \mathrm{sec}$ that is $10 \mathrm{~min}$ for $\mathrm{T}_{\text {gel }}$ and $120^{\circ} \mathrm{C}$ for the $\mathrm{T}_{\text {peak. }}$. In this study hence an optimal percentage of catalyst and accelerator would be at $5 \%$ and $4 \%$ respectively that has a peak temperature of around $125^{\circ} \mathrm{C}$ and $546 \mathrm{Sec}$. It is to be noted that the experiments of curing were conducted at room temperature.

\section{REFERENCES}

1. SachinWaigaonkar, B J C Babu\& Amit Rajpu (2011) Curing studies of unsaturated polyester resin used in FRP products. Indian Journal of Engineering\& Materials Sciences. 18: 31-39

2. Piotr Penczek, EwaRudnik, BogumitaArczewska, RyszardOstrysz,(1995) Curing of unsaturated polyester resins with low exotherm peak Polymer Science \& Technology Genera. 229:15-27

3. Nasr E S \& Azim A(1992) A, Polymer Advanced Technology, 3: 407-411.

4. H. V. Boenig (1964), Unsaturated Polyesters, Elsevier Publ. Co., Amsterdam, p. 154

5. Yang $H \&$ Lee L J (2000). J ApplPolymSci, Comparison of unsaturated polyester and vinylester resins in low temperature polymerization 79: 1230-1242.

6. V. Ravi Kumar, B. P. Dileep, and H. R. Vital; Tribological and mechanical characterization of Al-Ni-SiC metal matrix composites, AIP Conference Proceedings 1859 (2017), 020020.

7. Cook W D, Lau M, Mehrabi M, Dean K \& Zipper M(2001)PolymInt, Control of gel time and exothermbehaviour during cure of unsaturated polyester resins, Polymer International 50: 129-134.

8. N. Naderi, S. Mazinani, M. HosainBeheshty, M. Mahdi Rajab (2015) Cure kinetics of hot cured unsaturated polyester (UP)/nanoclay nanocomposite including dual initiators, Plastics, Rubber and Composites, 44 : 19-25

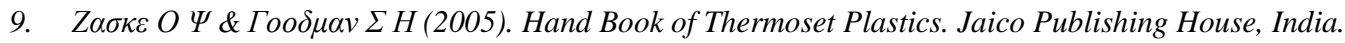

10. Fried J R (2005). Polymer Science \& Technology, Pearson Education, India.

11. Dyson R W(1998). Specialty Polymers, 2nd ed. Blackie Academic \& Professional, UK.

12. M.-J. Brekner and C. Feger (2003) Curing studies of a polyimide precursor. Journal of Polymer Science Part A: Polymer Chemistry 25: 7

13. T. Maity, B. C. Samanta, S. Dalai, A. K. Banthia, (2007) "Synthesis, characterisation and curing studies of BCCOMB", Pigment \& Resin Technology, 36: 30 - 38

14. Lakshmi. B, Shivananda. K. N, Mahendra. K. N. (2010) Synthesis, Characterization and Curing Studies of Thermosetting Epoxy Resin with Amines Department of Studies in Chemistry. Korean Chem. Soc. 31: 2272 - 2278

15. V. Ravi Kumar, B. P. Dileep, S. Mohan Kumar, and M. V. Phanibhushana, Effect of metal coatings on mechanical properties of alluinium alloy, AIP Conference Proceedings 1859 (2017), 020037-1 - 020037-6.

16. Dileep, B. P., RaviKumar, V. Prashanth Mrudula, and M. V. Phanibhushana, "Effect of zinc $\quad$ coating on mechanical properties of Al 7075", in Applied Mechanics and Materials, 592-594,

2014 pp, 255-259

17. Dileep B P, B, R, Sridhar, “A Investigation on Mechanical and Metallurgical Properties of Steel EN24 and SiC MMCs, International Journal of Mechanical and Production Engineering Research and Development (IJMPERD), Vol. 8, Issue 2, Apr 2018, 189-194 